\title{
RANCANG BANGUN PROTOTIPE GARDENING SMART SYSTEM (GSS) UNTUK PERAWATAN TANAMAN ANGGREK BERBASIS WEB
}

\author{
Deni Kurnia \\ Program Studi Teknik Mekatronika \\ Politeknik Enjinering Indorama \\ Email: deni.kurnia@pei.ac.id \\ Adolf Asih Suprianto \\ Program Studi Teknik Mekatronika \\ Politeknik Enjinering Indorama \\ Email: adolf@pei.ac.id
}

\begin{abstract}
ABSTRAK
Gardening Smart System (GSS) adalah protitipe sistem perawatan tanaman yang pengontrolannya dirancang melalui web. Prototipe ini dimaksudkan untuk membantu pengontrolan sistem perawatan tanaman berjenis anggrek pada tingkat perorangan (personal user) yang kedepannya dapat dikembangkan lebih luas lagi aplikasinya. Perancangan prototipe ini meliputi aspek hardware dan software. Dari sisi hardware prototipe dirancang menggunakan soil mosturise sensor, arduino, ethernet shield dan waterpump, sedangkan dari sisi software prototipe dirancang dengan membangun user interface berbasis HTML dan CSS. Komunikasi data antara software dengan hardware dilakukan melalui IP address yang dapat diakses melalui mobile phone (HP) maupun desktop/PC. Pengujian prototipe diterapkan pada salah satu tanaman anggrek berjenis Phalaenopsis. Setelah dilakukan pengujian pada aspek hardware dan software, hasil yang diperoleh sesuai dengan desain dan spesifikasi yang telah direncanakan. Kedepan, pengembangan prototipe ini masih terbuka lebar untuk mengontrol sistem berbasis web dengan aplikasi lebih kompleks lagi.
\end{abstract}

Kata kunci: aplikasi berbasis web, komunikasi data, IOT (internet of thing).

\section{ABSTRACT}

Gardening Smart System (GSS) is a plants prototype controlling system which is controlled using web application. The prototype is intended to control manifold orchid plant on the individual level (personal user) and in the future it could be developed more widely in many applications. The scope of design are focusing on hardware and software development. In terms of hardware side, we use mosturise soil sensor, arduino, ethernet shield and waterpump, and in terms of software side, we use HTML tag and CSS application to develop the user interface (UI). Mobile phone (HP) and desktop / PC can be use to control the data communication through IP address. Finally, we use one manifold orchid Phalaenopsis type for prototipe testing, and the results prototype has succesfully done and accordance with the specifications. In the future, the development of this prototype is still wide open for a web-based control system with more complex applications.

Keywords: web based aplications, data communication, IOT (internet of thing).

\section{PENDAHULUAN}

Gardening Smart System (GSS) adalah protitipe sistem perawatan tanaman yang pengontrolannya dirancang melalui web. Perancangan prototipe ini dimaksudkan untuk membantu pengontrolan sistem perawatan tanaman berjenis anggrek pada tingkat perorangan (personal user). Harapannya, penelitian prototipe ini dapat dikembangkan lagi untuk membantu meningkatkan produktivitas para petani anggrek di Indonesia ataupun penggunaan yang lebih luas lagi pada masa yang akan datang.

Dipilihnya tanaman anggrek sebagai media ujicoba penelitian ini didasari dari data yang diperoleh dari Balitbang Departemen Pertanian [5] bahwa peminat anggrek dari tahun ke tahun terus mengalami peningkatan, sampai tahun 2010 diperkirakan areal pertumbuhan komoditas anggrek di Sumatera Utara menjadi 20 ha, DKI Jakarta 51,8 ha, Jawa Barat 60 ha, Jawa Timur 100 ha, Kalimantan Timur 51,7 ha, Sulawesi Selatan 3,6 ha, dan Papua 99,4 ha. Menurut Balitbang, saat ini anggrek yang dominan disukai masyarakat adalah jenis Dendrobium (34\%), diikuti oleh Oncidium Golden Shower (26\%), Cattleya (20\%) dan Vanda (17\%) serta anggrek lainnya (3\%). Kelebihan lainya, anggrek dapat ditanam dalam kondisi lahan apapun, karena anggrek tidak memerlukan media tumbuh tanah. Namun yang perlu mendapat perhatian serius dalam pengembangan anggrek adalah kualitas $\mathrm{pH}$ air. 
Karena keterbatasan varietas anggrek yang dimiliki, penulis memilih Phalaenopsis amabilis (Anggrek bulan) sebagai media ujocoba. Anggrek ini merupakan tanaman anggrek monopodial yang menyukai sedikit cahaya matahari sebagai penunjang hidupnya. Daunnya berwarna hijau dengan bentuk memanjang. Akar-akarnya berwarna putih dan berbentuk bulat memanjang serta terasa berdaging. Bunganya memiliki sedikit keharuman dan waktu mekar yang lama serta dapat tumbuh hingga diameter $10 \mathrm{~cm}$ lebih [7].

Widi dan Heru (2014) [3] telah melakukan penelitian terhadap sistem penyiraman tanaman anggrek otomatis menggunakan sensor kelembaban dengan perancangan user interface menggunakan Delphi dan kontroler arduino berbasis $P C$ standalone. Dalam penelitian ini pengembangan user interface masih belum menggunakan web sebagai alat monitoring, sehingga perlu dilakukan pengembangan penelitian yang memungkinkan pengontrolan dapat dilakkan melalui web baik melalui $P C$ maupun mobile phone (HP).

\section{METODOLOGI PENELITIAN}

Prototipe ini menggunakan soil mosturise sensor yang berkualitas tinggi untuk menguji kelembaban media tempat tumbuh anggrek secara akurat. Material yang digunakan berbahan plat lapis nikel sehingga memperbesar area induksi, meningkatkan konduktivitas, mencegah masalah karat dan meningkatkan usia pakai. Sensor ini dapat membaca berbagai tingkat kelembaban $(\mathrm{pH})$ dengan pengaturan potensiometer [8].

Jika kelembaban tanah di bawah nilai yang di-set, maka sensor akan memberikan respon terhadap arduino. Sinyal yang masuk dapat dipilih baik analog maupun digital. Selanjutnya sinyal tersebut diproses untuk menentukan kapan pompa $O N$ atau $O F F$. Selain pompa dapat menyala dan mati secara otomatis, pemilik tanaman pun dapat mengendalikan pompa sesuai kebutuhan, melalui koneksi web yang dapat diakses baik melalui dekstop maupun mobile (HP). Skema bagaimana sistem ini bekerja dapat digambarkan sebagai berikut (Gambar 1) :

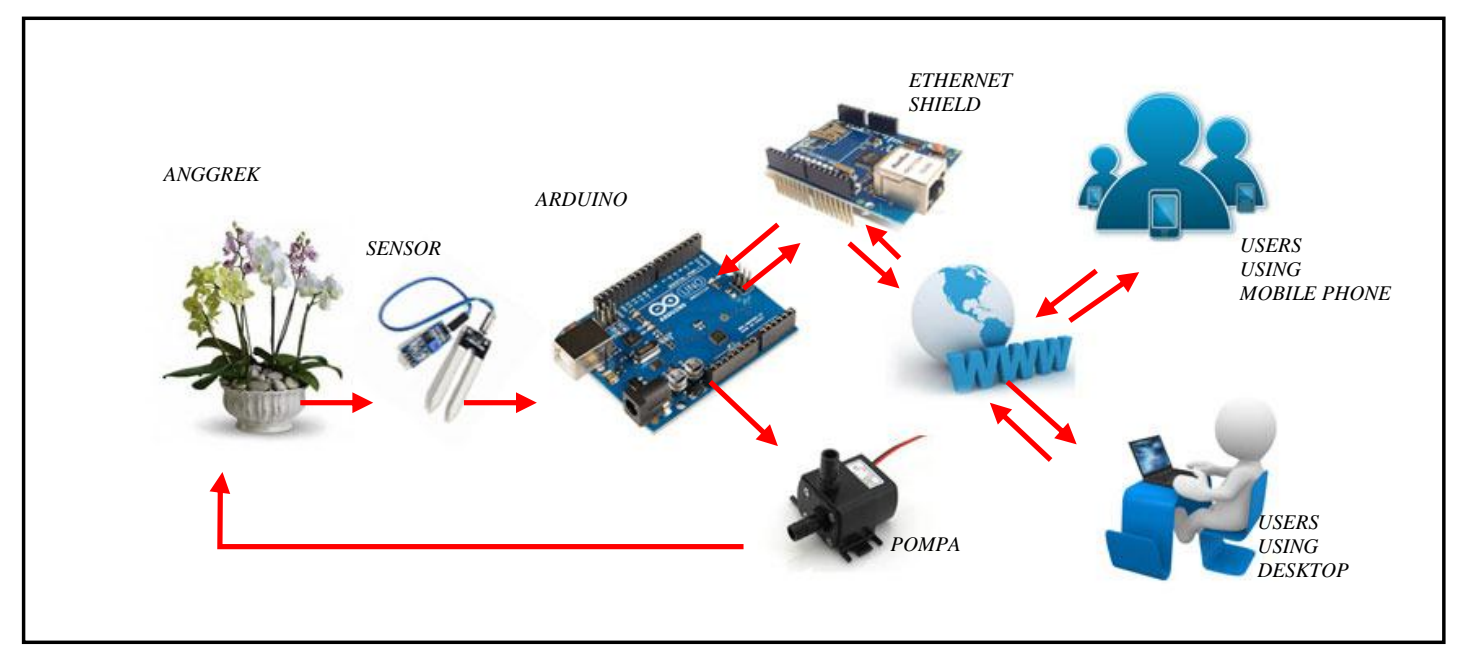

Gambar 1. Sistem kerja prototipe Gardening Smart System (GSS)

Data kelembaban tanah yang diperoleh melalui sensor, selain diproses arduino untuk men-trigger relay (kondisi $O N-O F F$ pompa), pengontrolan pun dapat dilakukan melalui web dengan menambahkan modul ethernet shield. Melalui modul ini, pengontrolan dapat dilakukan melalui IP Address yang dapat diakses oleh berbagai macam browser.

Jadi dalam penelitian ini, dilakukan kegiatan sebagai berikut :

a. Dari sisi hardware : membuat prototipe Gardening Smart Sytem (GSS) yang dibangun menggunakan sensor, arduino, modul ethernet, relay dan pompa air.

b. Dari sisi software : membuat aplikasi berbasis web yang berfungsi untuk melakukan pengontrolan prototipe tersebut.

c. Obyek penelitian untuk menguji protitipe ini adalah anggrek Phalaenopsis amabilis.

Langkah awal dalam penelitian ini adalah dengan mendapatkan data nilai kelembaban tanah yang dapat dideteksi oleh soil moisture sensor ( $f$ c 28) seperti dijelaskan pada tabel 1 [8].

Tabel 1. Nilai kelembaban tanah

\begin{tabular}{ccc}
\hline Nilai Kelembaban & Nilai yang diproses oleh & Kondisi Tanah \\
Tanah $(\boldsymbol{p H})$ & Arduino & Kering \\
\hline $0<$ nilai $<300$ & $0<$ nilai $<30$ & Lembab \\
$300<$ nilai $<700$ & $30<$ nilai $<70$ & Basah \\
$700<$ Nilai $<950$ & $70<$ Nilai $<95$ & \\
\hline
\end{tabular}


Catatan:

a. Rentang nilai kelembaban tanah $(\mathrm{pH}) 0$ sd 950 adalah rentang nilai analog yang dapat dibaca oleh soil moisture sensor berdasarkan data sheet-nya.

b. Nilai yang diproses Arduino adalah nilai konversi dengan perhitungan : (Nilai Kelembaban Tanah/10)

Gambar 2 menjelaskan skema wiring diagram pada soil moisture sensor, dimana sensor dibangun dengan menggunakan komparator LM393 sehingga outputnya selain diperoleh data analog, juga bisa berupa data digital.

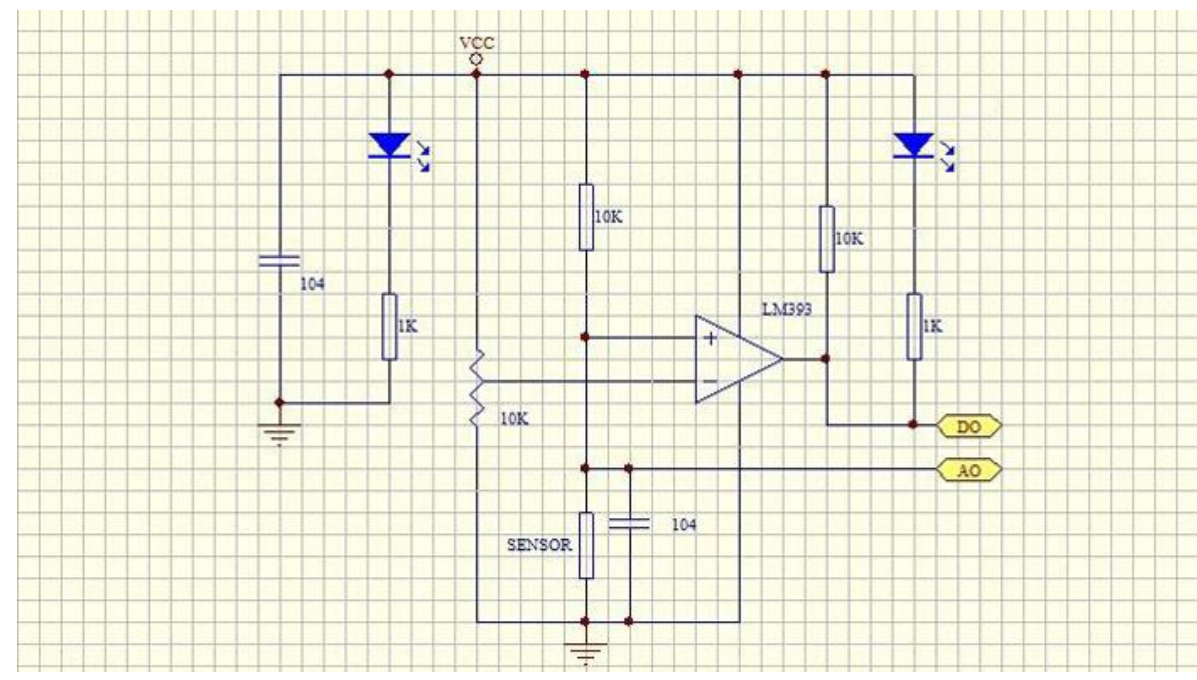

Gambar 2. Schematic Diagram Soil Moisture Sensor

Proses pengolahan data dilakukan melalui sketch arduino dengan spesifikasi sebagai berikut :

a. Arduino yang digunakan adalah arduino uno ver 3 .

b. Sensor soil moisture dihubungkan dengan PIN Analog AO.

c. Relay dan LED biru indikator pompa ON dihubungkan dengan PIN Digital D9.

d. Pompa akan berhenti jika tanah sudah terdeteksi lembab oleh sensor.

e. Jika terjadi kegagalan deteksi nilai sensor, untuk menghindari pompa menyala terus, maka pompa akan mati setelah menyala 1 menit.

f. LED merah indikator tanah lembab (pompa $O F F$ ) dihubungkan dengan PIN Digital D8.

g. LED hijau indikator tanah basah (pompa OFF) dihubungkan dengan PIN Digital D7.

h. Komunikasi ke web menggunakan modul ethernet shield melalui PIN Digital D10, D11, D12, D13.

Gambar 3 berikut menjelaskan spesifikasi rancangan diatas:

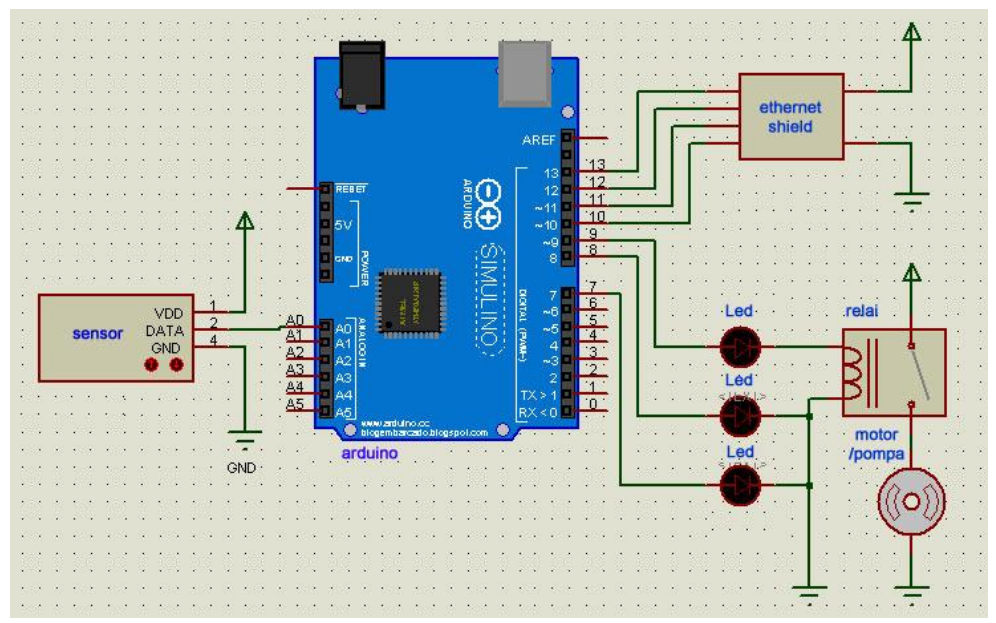

Gambar 3. Schematic Diagram Gardening Smart System

Adapun diagram alur bagaimana prototipe bekerja dapat dijelaskan pada gambar 4 : 


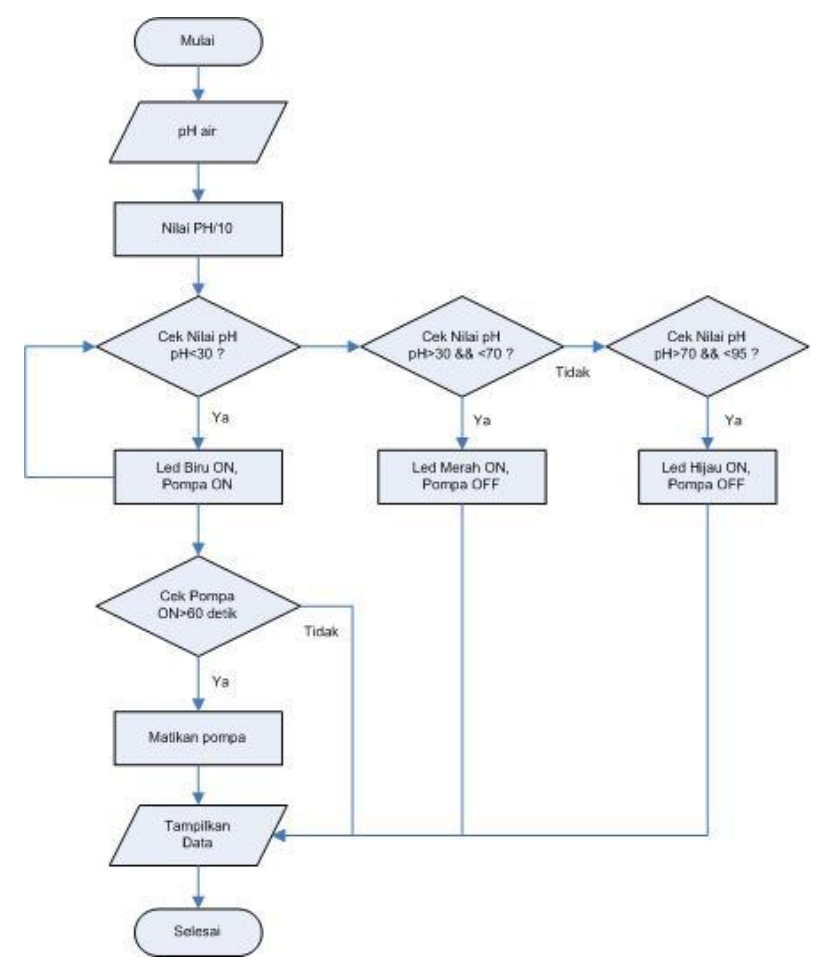

Gambar 4. Diagram Alur Gardening Smart System pada sisi hardware

Selanjutnya penulis memilih arduino sebagai alat kontrol, didasari oleh pertimbangan bahwa arduino adalah board yang mudah didapat, open source, serta banyak memiliki library yang dapat digunakan untuk mengembangkan aplikasi yang sesuai dengan kebutuhan penulis, dalam merancang prototipe ini.

Terkait keuntungan menggunakan arduino, Michael McRobert (2010) [2] mengatakan bahwa salah satu kelebihan arduino dibandingkan dengan mikrokontroler yang lain adalah bahwa arduino merupakan platform yang mudah digunakan, karena penggunanya tidak harus selalu memiliki background yang spesifik di bidang elektronika. Pengguna arduino dapat mengembangkan berbagai macam prototipe dalam waktu yang relatif singkat tanpa harus kesulitan mendapatkan referensi informasi, karena komunitas penggunanya selalu saling berbagi code/sketch, library maupun skema rangkaian yang tersebar di berbagai macam forum komunitas pengguna arduino. Dengan arduino, membuat suatu prototipe berbasis mikrokontroler menjadi mudah dilakukan oleh semua orang (Margolis, 2011) [1].

Dari sisi software, user interface yang akan digunakan untuk pengontrolan, menggunakan tag $H T M L$ dan CSS. HTML adalah bahasa markup yang memungkinkan kita mendesain user interface yang support terhadap berbagai macam browser. Sedangkan CSS mendukung HTML untuk memperindah tampilan halaman agar lebih interaktif dan user friendly. Ed Tittel and Chris Minnick (2013) [4] mengatakan bahwa halaman web dapat mengakomodasi berbagai macam kebutuhan untuk menampilkan konten seperti teks, grafik, audio dan video, streaming media, bahkan game interaktif. Oleh karena itu web menjadi salah satu media yang dipilih untuk menampilkan user interface yang berfungsi untuk mengontrol Gardening Smart System (GSS) yang dapat diakses baik melalui mobile phone (HP) mapun desktop (PC). Pada tahap perancangan software, penulis membuat gambar visualisasi user interface untuk mengakses prototipe via mobile phone (HP) (Gambar 5) dan via desktop (Gambar 6).

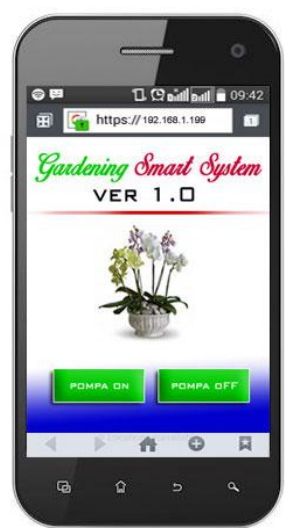

Gambar 5. Rancangan user interface saat diakses melalui mobile phone 


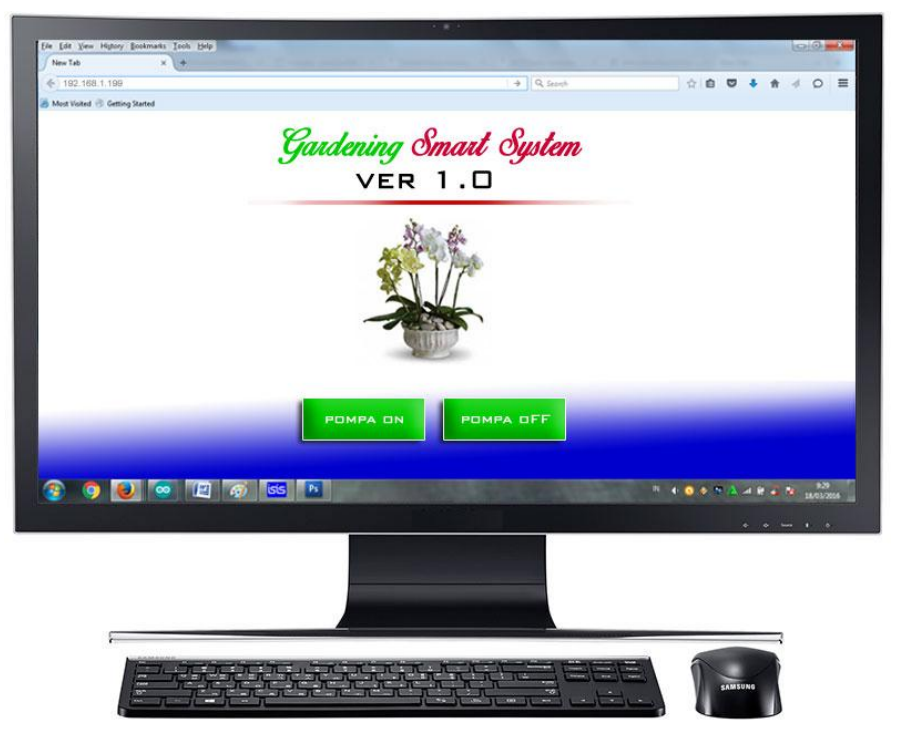

Gambar 6. Rancangan user interface saat diakses melalui desktop berikut :

Untuk merealisasikan proses perancangan software, dalam penelitian ini dilakukan langkah-langkah sebagai

a. Agar software bisa berkomunikasi melalui ethernet shield pada arduino, maka sketch ditambahkan library:

\#include $<$ SPI.h>

\#include <Ethernet.h>

b. Menentukan IP Address pada sketch sesuai dengan lokasi jaringan tempat penulis melakukan ujicoba.

c. Menambahkan microSD pada ethernet shield untuk menyimpan file HTML yang akan dibuat.

d. Menambahkan library \# include $\langle\mathrm{SD} . \mathrm{h}\rangle$ dan menambahkan baris program sbb:

$/ / \ldots$

File webFile;

void loop ()

\{

$/ / \ldots$

webFile = SD.open ("index.htm");// buka file web

if (webFile)

\{

while (webFile.available())

\{

client.write(webFile.read()) ; // kirim halaman web

\}

webFile.close ( ) ;

$/ / \ldots$

e. Membuat tag $H T M L$ dan menggabungkannya dengan CSS menggunakan text editor sesuai rencana tampilan yang akan dibuat.

f. Menyalin file index.htm dan style.css kedalam microSD.

\section{HASIL PENELITIAN DAN PEMBAHASAN}

Pengujian prototipe dilakukan melalui tiga tahap:

a. Pengujian fungsi hardware secara terpisah.

b. Pengujian fungsi software secara terpisah.

c. Pengujian komunikasi hardware dan software secara bersamaan.

Pengujian tahap pertama dilakukan dengan cara menghubungkan hardware dengan anggrek jenis Phalaenopsis amabilis (anggrek bulan) melalui sensor dengan dua kondisi tanah yaitu kering dan basah (gambar 7). 


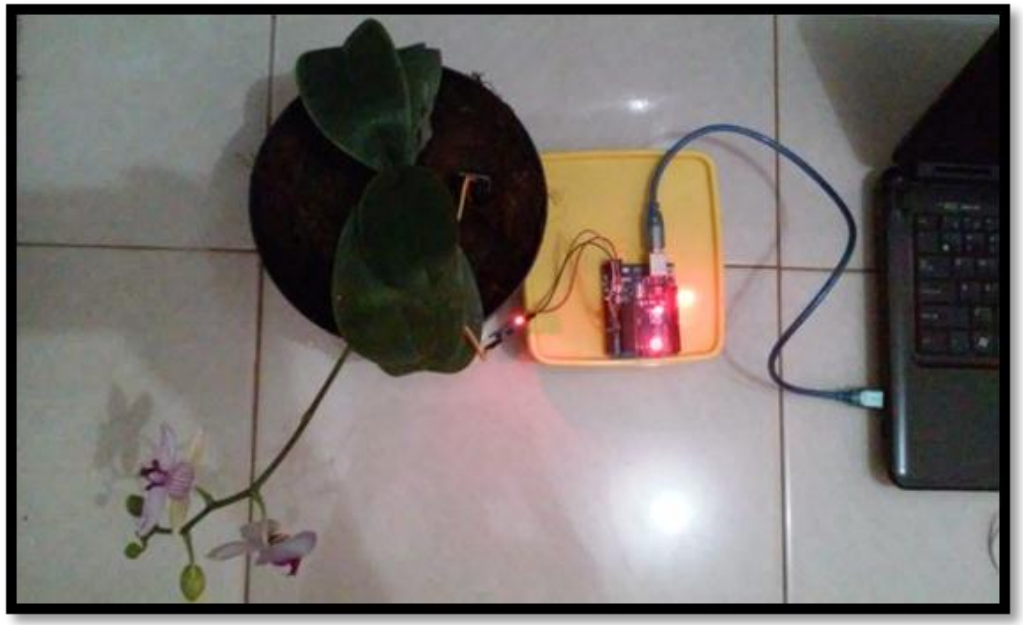

Gambar 7. Pengujian prototipe pada sisi hardware dengan tanaman Anggrek

Hasil pengujian hardware secara terpisah dilakukan melalui serial monitor pada IDE Arduino dengan hasil sebagai berikut (Gambar 8 \& 9):

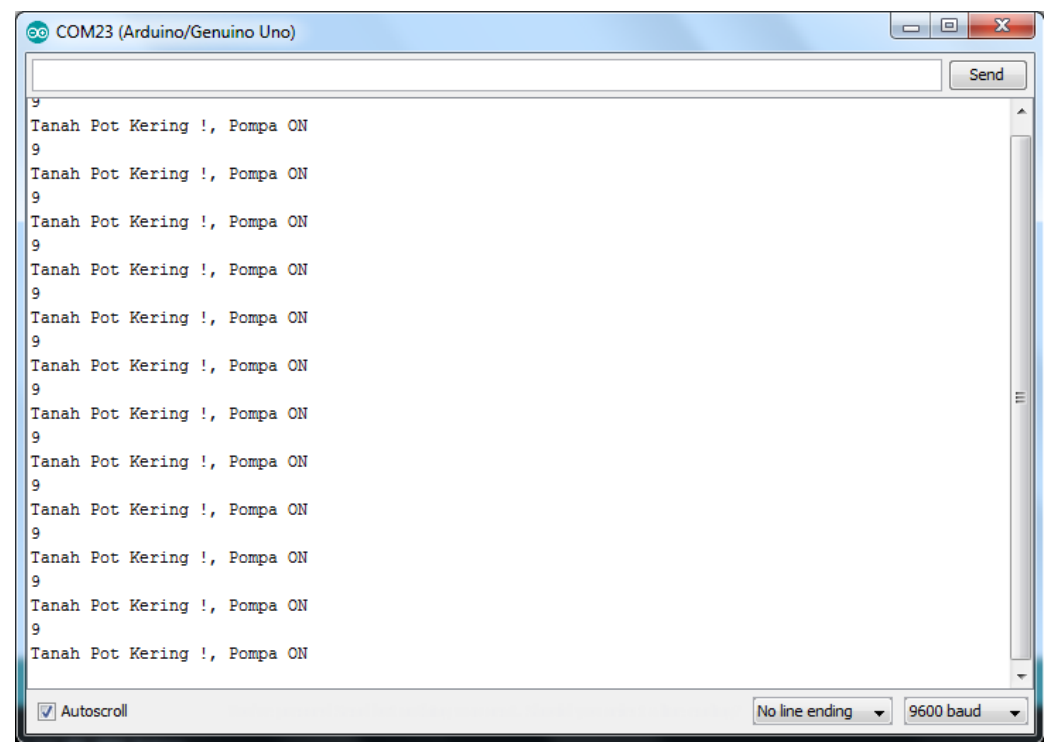

Gambar 8. Kondisi tanah kering $(p H<30)$

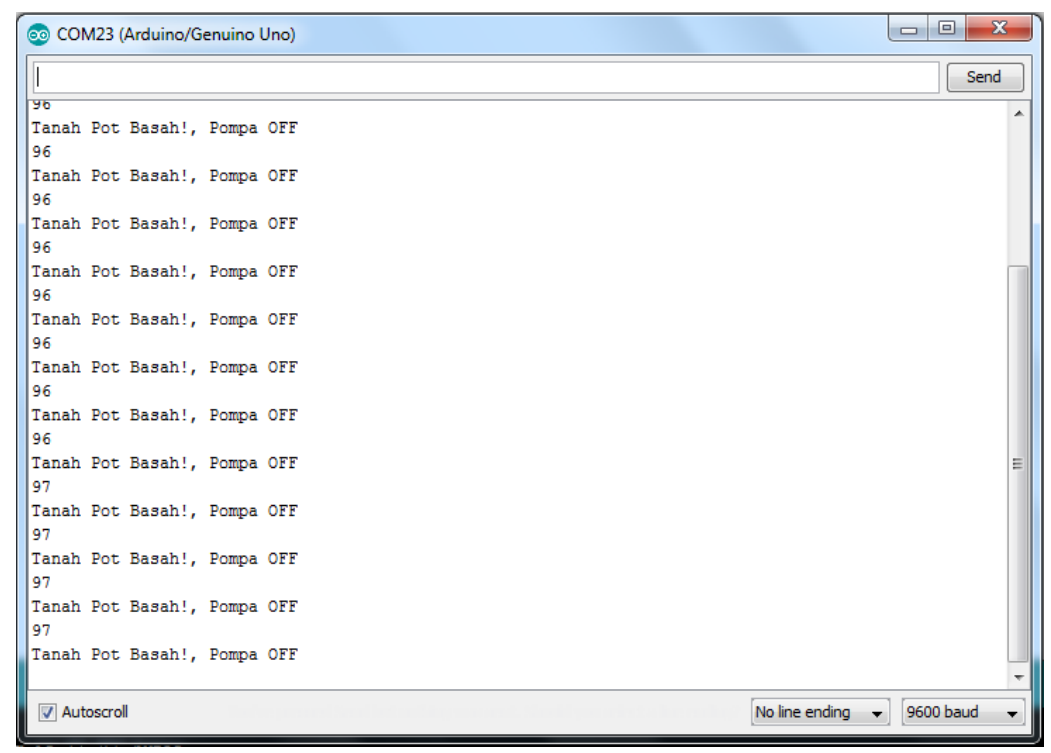

Gambar 9. Kondisi tanah basah $(p H>70)$ 
Pada pengujian tahap kedua yaitu bagian software, penulis melakukan langkah sebagai berikut :

a. Menggunakan browser mozila dan chrome pada desktop saat menjalankan file index.htm.

b. Menggunakan browser default OS android dan chrome pada handphone saat menjalankan file index.htm.

c. Melakukan uji fungsi button $O N-O F F$ pada user interface.

Hasil pengujian dapat dijelaskan pada tabel 2 :

Tabel 2. Pengujian Fungsi Software saat belum terhubung ke hardware

\begin{tabular}{|c|c|c|c|}
\hline Nama Device & Aspek yang diuji & Metode & Hasil \\
\hline $\begin{array}{c}\text { Handphone - OS } \\
\text { Android-browser } \\
\text { default }\end{array}$ & $\begin{array}{c}\text { Fungsi program, } \\
\text { UI/grafis, respon waktu } \\
\text { akses, respon button }\end{array}$ & $\begin{array}{l}\text { Request index.htm, } \\
\text { coba click button }\end{array}$ & $\begin{array}{c}\text { Program berfungsi } \\
\text { dengan baik, respon } \\
\text { waktu akses antara 1-2 } \\
\text { detik, button berfungsi } \\
\text { dengan baik. }\end{array}$ \\
\hline $\begin{array}{c}\text { Handphone - OS } \\
\text { Android-browser } \\
\text { chrome }\end{array}$ & $\begin{array}{l}\text { Fungsi program, } \\
\text { UI/grafis, respon waktu } \\
\text { akses, respon button }\end{array}$ & $\begin{array}{l}\text { Request index.htm, } \\
\text { coba click button }\end{array}$ & $\begin{array}{c}\text { Program berfungsi } \\
\text { dengan baik, respon } \\
\text { waktu akses antara 1-2 } \\
\text { detik, button berfungsi } \\
\text { dengan baik. }\end{array}$ \\
\hline $\begin{array}{c}\text { PC Desktop-OS } \\
\text { Windows7-Browser } \\
\text { mozilla }\end{array}$ & $\begin{array}{l}\text { Fungsi program, } \\
\text { UI/grafis, respon waktu } \\
\text { akses, respon button }\end{array}$ & $\begin{array}{l}\text { Request index.htm, } \\
\text { coba click button }\end{array}$ & $\begin{array}{c}\text { Program berfungsi } \\
\text { dengan baik, respon } \\
\text { waktu akses antara 1-2 } \\
\text { detik, button berfungsi } \\
\text { dengan baik. }\end{array}$ \\
\hline $\begin{array}{c}\text { PC Desktop-OS } \\
\text { Windows7-Browser } \\
\text { chrome }\end{array}$ & $\begin{array}{l}\text { Fungsi program, } \\
\text { UI/grafis, respon waktu } \\
\text { akses, respon button }\end{array}$ & $\begin{array}{l}\text { Request index.htm, } \\
\text { coba click button }\end{array}$ & $\begin{array}{c}\text { Program berfungsi } \\
\text { dengan baik, respon } \\
\text { waktu akses antara 1-2 } \\
\text { detik, button berfungsi } \\
\text { dengan baik. }\end{array}$ \\
\hline
\end{tabular}

Tabel 3. Pengujian Fungsi software saat dihubungkan ke hardware (server)

\begin{tabular}{|c|c|c|c|}
\hline Nama Device & Aspek yang diuji & Metode & Hasil \\
\hline $\begin{array}{c}\text { Handphone - OS } \\
\text { Android-browser } \\
\text { default }\end{array}$ & $\begin{array}{l}\text { Fungsi program, UI/grafis, } \\
\text { respon waktu repply dari } \\
\text { server, respon button }\end{array}$ & $\begin{array}{c}\text { Request IP Adress, coba } \\
\text { click button } \\
\text { POMPA ON-OFF }\end{array}$ & $\begin{array}{c}\text { Program berfungsi dengan } \\
\text { baik, respon waktu repply } \\
\text { dari server antara 3-5 detik, } \\
\text { button ON ditekan, pompa } \\
\text { ON, button OFF ditekan, } \\
\text { pompa } O F F\end{array}$ \\
\hline $\begin{array}{c}\text { Handphone - OS } \\
\text { Android-browser } \\
\text { chrome }\end{array}$ & $\begin{array}{l}\text { Fungsi program, UI/grafis, } \\
\text { respon waktu repply dari } \\
\text { server, respon button }\end{array}$ & $\begin{array}{c}\text { Request IP Adress, coba } \\
\text { click button } \\
\text { POMPA } O N-O F F\end{array}$ & $\begin{array}{c}\text { Program berfungsi dengan } \\
\text { baik, respon waktu repply } \\
\text { dari server antara 3-5 detik, } \\
\text { button } O N \text { ditekan, pompa } \\
\text { ON, button } O F F \text { ditekan, } \\
\text { pompa } O F F\end{array}$ \\
\hline $\begin{array}{c}\text { PC Desktop-OS } \\
\text { Windows7-Browser } \\
\text { mozilla }\end{array}$ & $\begin{array}{l}\text { Fungsi program, UI/grafis, } \\
\text { respon waktu repply dari } \\
\text { server, respon button }\end{array}$ & $\begin{array}{c}\text { Request IP Adress, coba } \\
\text { click button } \\
\text { POMPA ON-OFF }\end{array}$ & $\begin{array}{c}\text { Program berfungsi dengan } \\
\text { baik, respon waktu repply dari } \\
\text { server antara 3-5 detik, button } \\
\text { ON ditekan, pompa ON, } \\
\text { button OFF ditekan, pompa } \\
\text { OFF }\end{array}$ \\
\hline $\begin{array}{c}\text { PC Desktop-OS } \\
\text { Windows7-Browser } \\
\text { chrome }\end{array}$ & $\begin{array}{l}\text { Fungsi program, UI/grafis, } \\
\text { respon waktu repply dari } \\
\text { server, respon button }\end{array}$ & $\begin{array}{c}\text { Request IP Adress, coba } \\
\text { click button } \\
\text { POMPA ON-OFF }\end{array}$ & $\begin{array}{c}\text { Program berfungsi dengan } \\
\text { baik, respon waktu repply dari } \\
\text { server antara 3-4 detik, button } \\
\text { ON ditekan, pompa ON, } \\
\text { button OFF ditekan, pompa } \\
\text { OFF }\end{array}$ \\
\hline
\end{tabular}

Pada tahap akhir penelitian, pengujian dilakukan dengan cara monitoring prototipe selama satu minggu dan me-record data kelembaban tanah mengunakan data logger dengan hasil sebagai berikut : 


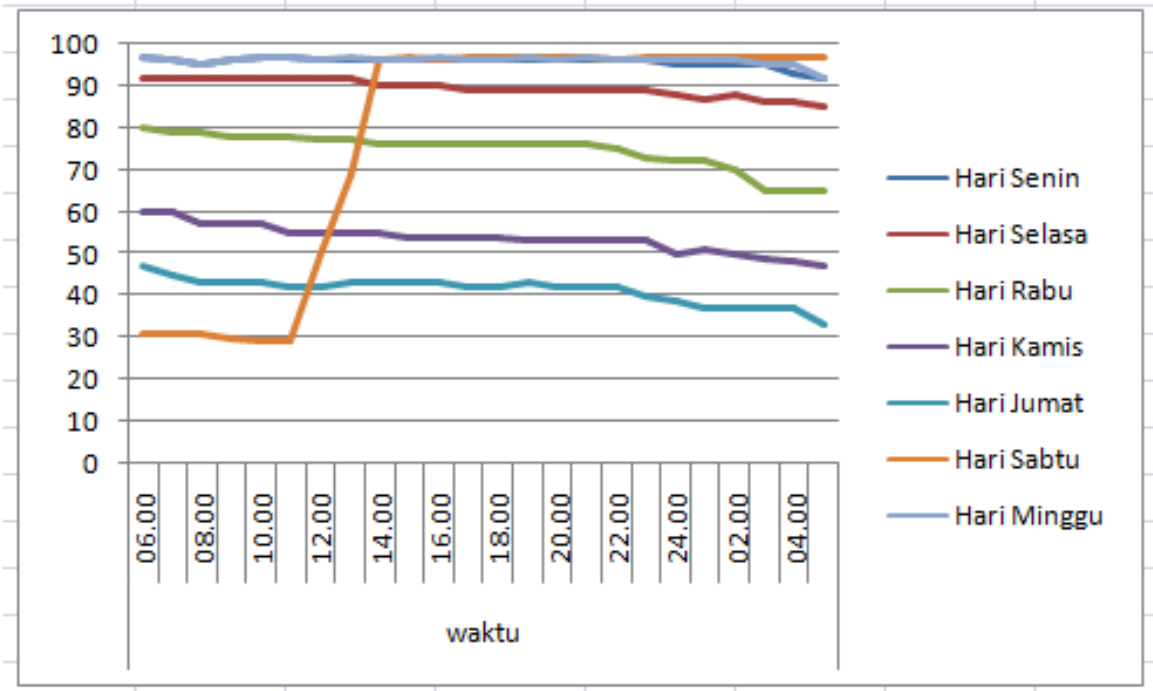

Gambar 10. Grafik monitoring nilai $\mathrm{pH}$ selama satu minggu

\section{KESIMPULAN}

Setelah melewati tahap desain, implementasi dan evaluasi, diperoleh kesimpulan sebagai berikut :

a. Prototipe dapat berfungsi dengan baik, hardware dan software dapat berkomunikasi melalui aplikasi web.

b. Kadar kelembaban tanah $(p H)$ dapat dikontrol secara otomatis dan dijaga kondisinya agar tetap diatas 30 , pada saat $p H<30$, maka secara otomatis $L E D$ indicator biru menyala. Disaat yang sama pompa menyala selama 1 menit.

c. Selain mode otomatis, user pun dapat menggunakan mode manual dengan cara menyalakan dan mematikan pompa melalui web.

d. Ketika dilakukan ujicoba monitoring selama seminggu, $\mathrm{pH}$ terus berubah dan menurun sampai hari keenam. $p H$ naik kembali ke posisi $>70$ setelah pompa menyala dan mengalirkan air secara otomatis kedalam pot anggrek.

e. Secara keseluruhan, protipe yang dibuat sesuai dengan perencanaan yang dilakukan dalam metodologi penelitian.

f. Prototipe dapat dikembangkan untuk scope pengontrolan tanaman yang lebih banyak lagi.

\section{DAFTAR PUSTAKA}

[1] Margolis, Michael, 2011. Arduino Cookbook, O’Reilly Media, Inc., 1005 Gravenstein Highway North, Sebastopol, CA.

[2] McRoberts, Michael, 2010. Beginning Arduino, Apress, Springer, New York.

[3] Nugrahaning Widhi, Happy, dan Winarno Heru, 2014. "Sistem Penyiraman Tanaman Anggrek Menggunakan Sensor Kelembaban dengan Program Borland Delphi 7 Berbasis Modul Arduino Uno”, GEMA TEKNOLOGI Vol. 18 No. 1 Periode April 2014 - Oktober 2014, hal 41-45.

[4] Tittel, Ed, and Minnick, Chris, 2013. Beginning HTML5 \& CSS3 For Dummies, John Wiley \& Sons, Inc., Hoboken, New Jersey.

[5] __ 2005, Prospek dan Arah Pengembangan Agribisnis Anggrek, Balitbang Departemen Pertanian, Pasar Minggu, Jakarta Selatan, Indonesia.

[6] _ _ https://startingelectronics.org/tutorials/arduino/ethernet-shield-web-server-tutorial/SD-cardweb-server/, diakses 2 Maret 2015 Pukul 08.35 WIB.

[7] __, https://id.wikipedia.org/wiki/Anggrek_bulan, diakses 4 Maret 2015 Pukul 09.40 WIB.

[8] _ _ http://www.dfrobot.com/wiki/index.php?title=Moisture_Sensor_\%28SKU:SEN0114\%29 , diakses Maret 2015 Pukul 11.35 WIB 